\title{
The Application of Media Asset Management System in Television Program Operation
}

\author{
Xi Wang \\ School of Humanities and Laws \\ Tianjin Polytechnic University \\ Tianjin, China \\ wangxi@tjpu.edu.cn
}

\author{
Haining Dong \\ School of Humanities and Laws \\ Tianjin Polytechnic University \\ Tianjin, China \\ donghaining_tjpu@163.com
}

\begin{abstract}
Summarized the related concepts of the Media Asset Management System. Detailed analyzed the application of Media Asset Management System in the Television Programme in operation. The Media Asset Management System will enhance the core competence of TV media, reconstruct the value chain of $\mathrm{TV}$ media which makes program contents as the core, and enhance the ability to achieve a variety of value of the TV media. Media Asset Management System will be applied more widely in the development of television media.
\end{abstract}

Keywords-Media Asset Management System; television program operation; application

After the development of more than half a century of radio and television industry, the number of the programs have been dramatic increased.The information of audio and video expanded unprecedented. The traditional ways of preserve and use of tape-media programs lead to that radio and television media face the grim problem of the storage of programs. At the same time, because of the rapid development and popularization of network technology, the storage and transmission of television programs have been transformed from analog to digital. Also, the revolutions in technology are driving the change in the concept of program production. The digitization and networking of radio and television has developed from a local digital network to digital local area network. The application of Media Asset Management System has become the inevitable choice to improve the core competitiveness of TV media.

According to the current research and practice environment, Media Asset Management (MAM) generally refers specifically to Digital Media Asset Management. It is a manage process that using advanced technology and scientific concepts and methods, based on the Media Asset Management System(MAMS). It plans, organize, store, control and utilize the media content assets. The purpose is to co-ordinate the asset utilization, and maximize the value of it[1].

Digital Media Asset Management System is a kind of comprehensive management system. It not only can achieve the digital storage, cataloging, retrieval query, non-woven material transcoding and information release of various types of video information, audio information, text, charts, as well as other media information, but also can manage the equipment and fixed assets in a comprehensive way. Figure 1 is the workflow of Media Asset Management System.
The conception of Media Asset Management System is a kind of ideological innovation and progress. It is a way for TV media to improve the core competitiveness under the condition of the fierce market competition. With the idea of Media Asset Management has been paid more and more attention in the television industry, it is bound to cause changes in the field of media competition mode.

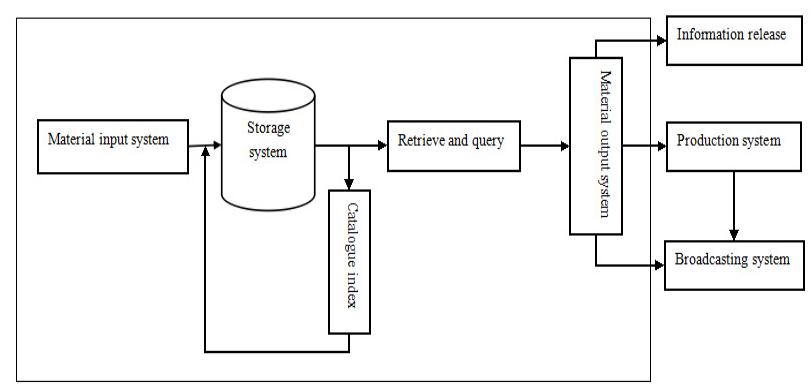

Figure 1. The workflow of Media asset management system.

I. Media Asset Management WiLl BeCome the BASIC WAY TO ENHANCE THE CORE COMPETITIVENESS OF TV MEDIA

With the emergence of various new media, the situation of TV media in the market competition is becoming more and more serious. Only have a strong core competitiveness, the TV media industry can attract the audience's attention persistently and be in an invincible position in the fierce market competition. In the current media environment, only in the implementation of digital media asset management, TV media industry can achieve the transformation of the resources to the asset and potential value to real value. In essence, we need not only the technology, but also a new dynamic operation mode, a flexible and efficient business process and an uniform and normative industry standard to enhance the core competence of TV media.

\section{A. The meaning of the core competence of TV media}

The concept of core competence was first put forward by C. K. Prahalad and G. Hamel in 1990.It means "knowledge and skills after the integration in an organization, especially the knowledge and skills about how to coordinate diverse production skills and integrate different technologies." This definition emphasizes the integration of knowledge and skills 
in the enterprise's products and services. Core competence is a combination of the elements such as talent, technology, equipment, philosophy and so on. It's a necessary condition for business survival and it's the primary source of an organization's competitive advantages.

The core competitiveness of TV media is refers to the television media has media hardware resources(such as the latest technology, equipment, scale of resource, media network coverage area and so on)and software resources (including media technology personnel, marketing management team, columns and channel brands, etc.)that won't be copied absolutely and the unique ability by optimize integrated marketing to make the television media to cope with the market competition[2]. Each kind of ability can constitute the core competitive advantage in different television media and different ability decides advantage in a particular aspect for a media organization.TV media should make full use of these abilities to form their own core competitiveness. They will stand out in the key competition from other media, get their own audience, win the ratings and market and achieve economic and social benefits.

\section{B. The practice exploration of using the Media Assets Management to enhance the competitiveness of the media}

With the rise of new media symbolized by Internet and the arrival of the digital age, the traditional TV industry felt great pressure. With the help of new communication technology, they tried to seek industrial upgrading and transformation. The introduction of Media Asset Management brought an opportunity for industrial transformation and upgrading of television media, proposed a new path for the television media to enhance their core competitiveness and put them in a favorable position in the intense media market competition.

In the early 1990s, the worldwide television media such as $\mathrm{BBC}$ and $\mathrm{CNN}$ has invested heavily in the construction of media asset management center. They regarded the media asset management as an important means to enhance their core competitiveness and gradually formed a Archive Mode with the goal of sharing data management, multimedia distribution pattern with the multi-channel sharing as the core and a full-flow media property management model on the basis of media property, linking producing and marketing.

Since the new century, Some domestic television stations also recognized the contribution of Media Asset Management to enhance the core competitiveness of the media and began to explore the management model of media asset.

At the beginning of this century, CCTV spent heavily to build Asia's largest and most technologically advanced audio-visual Archive. The number of inventory program data was more than a million discs. Zhao Huayong, the director of CCTV, said: Video data just like an inexhaustible mountain, it depends on you how to develop it. We can't keep the mountain without using it. Followed CCTV, Shanghai Culture, Radio and Television Group also started digital rebuild for the original Shanghai audio archives. Liaoning TV is the first provincial TV to apply Media Asset
Management System. After that, Guangxi TV and Chongqing TV station have also started the application of Media Asset Management System.

\section{THE VALUE CHAIN OF TV MEDIA WHICH MAKES} PROGRAM CONTENTS AS THE CORE WILL BE RECONSTRUCTED By Media Asset Management System.

Nowadays, the competition of media has entered a new era called "the content is the king.".For the television station, programs and materials has become more and more essential as strategic resources. Only have a good new "content" can the media attract the audience' attention, and thus get advertising revenue. Yet, it becomes more difficult for TV media to come up with attractive contents for the shock of new media and restrictions generated by production patterns of old contents from TV media. Even if you produced good contents, a series of questions like how to manage it, how to make it value-added, and so on, will still make a headache. In fact, Media Asset Management System has provide a full range of solutions including content creation, content storage, content distribution and reuse. Media Asset Management System will help TV media to reconstruct a new value chain which makes contents as the core.

\section{A. Media Asset Management System provides convenient content storage.}

Using the Media Asset Management System, the TV station can list, retrieve, store and manage encryption the accumulated and new produced materials and programs. It's a convenient way to check and reuse. Through the whole management process, the quality of materials and programs can't be damaged for the improper storage, and the TV station also don't need to worry about whether the storage space is enough or not, or you can't find the material you need. Resources can flow among the television medias established Media Asset Management System,also programs can establish new combinations. For example, if Tianjin TV want to make a documentary about the culture in Jing-jin region how to influence and blend each other. But Tianjin TV station possess abundant local information, while Beijing region just have a little program materials. Tianjin TV station can seek and gather the historical materials of Beijing in BTV or CCTV through Media Asset Management System. This not only saves the costs which pay for the staff who go out to interview and record, but also save time and cost, and enhance the programs' quality.

\section{B. Media Asset Management System provides abundant foundations of program contents}

A complete value chain of TV media industry including the originality, production, broadcast,sales, service and other aspects of TV media products. Different enterprises take part in different sectors have, and play different roles, finally get corresponding interest. The specific content of value chain of TV media industry mainly includes the capital operation of media, content operation, after operation, the content industry downstream products, extend channel network, advertisement and audience feedback, and so on[3].The value chain of TV media industry is based on some certain 
television content products or services. Such as Disney, Bertelsmann, News Corp. and other transnational media groups, their industry value chains are all based on the content production.

Which plays the most important role in the value chain of the TV media industry is the content providers. Because only with enough program content for broadcast, can TV media attract the audience and seize the market, then proceed. The TV media is supposed convert "production for broadcast" into "production for market" and be the base of production and dissemination. The TV media which has a complete, healthy content industry value chain can help sharing content resources by Media Asset Management System, and then realize the content asset value-added.

According to Prahalad and Hamel's summary of the concept of competitiveness, it is not difficult to see that the integration of its internal resources should be considered in the process of establishing the value chain of $\mathrm{TV}$ media industry .Only gathered the scattered resources can make it efficient and guarantee the quality of the products. The Media Asset Management System can classify and store the abundant resources possessed by TV media effectively, and the integrated resources are easy to be found during the process of TV media production.

\section{MEDIA ASSET MANAGEMENT SYSTEM WILL IMPROVE THE TV MEDIA'S ABILITY TO IMPLEMENT MANY KINDS OF VALUE}

\section{A. Media asset management system can make innovation to the value chain of TV content.}

Having been introduced into TV media, "the media asset management" replace the previous "send broadcast" link and become a new node link. To a certain extent, the media asset management system innovates the value chain of television content. After the purchase of production materials, finishing the content production, the TV station send out these products by media asset management system. In addition to traditional advertisers, the customers of TV station include the TV stations at all levels, content producers, new media operators and individual users. Different customers get the content they need from the TV station, sell out after creat them or watch directly. In this way the earnings of TV station increase greatly.

"long-tail theory", put forward by Chris Anderson, pointed out that long tail of the product category is longer than we thought. The more you supply, the more they demand and the long tail will continue to extend.(Figure 2) In this view, after getting more customers, although TV media will increase transaction costs, and there is only a little additional investment. As long as the programs based on the media asset management reasonably priced, the total revenue of TV station will be increased only and not be reduced.If the TV media expand the supply of media resource library, operate the media assets effectively and extend the market long tail,it would get long-term infinite profits.

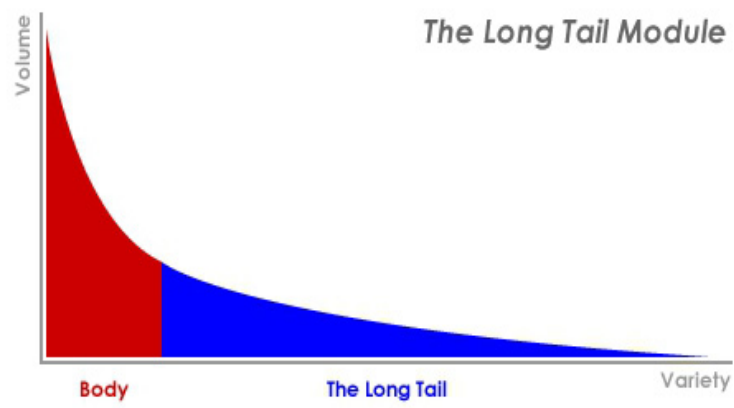

Figure 2. The Long Tail Module.

\section{B. Media asset management system can improve the economic benefits of $\mathrm{TV}$ media}

Taking the Media Asset Management System as the core broadcast sales platform could change the single profit mode of TV media and improve the economic benefits. At present, the domestic TV media mainly gets profit by means of increasing better ratings in order to win advertising revenue. However, advertising competition is becoming more intense nowadays, and TV media cannot run well alone relying on the advertising revenue. So TV media should transform the single profit model into a double profit model, which the later model can combine the advertising revenue and management fee income. Value-added services of TV such as Interactive TV, pay channel, video on demand are the core of this profit model. The quantity, content quality, television content industry scale directly influence the development of the business. Quantity and quality of the programme content and the scale of the TV content industry can make a direct affect on the business. While, the media asset management system can solve these problems effectively.

The development of Digital Pay TV in China is still immature.If the Digital Pay TV want to achieve high proceeds, They must analyze these particular audience, understand their viewing habits and provide unique programs and services for them. At present, the programme resources of Pay TV channels are still relatively scarce. If we can use the rich data in the media repository, we would ease the shortage of programme caused by the source shorted. Relying on the media asset library, the development and utilization of Digital Asset will greatly improve the television media organization's competitive advantage.

\section{ACKNOWLEDGMENT}

The research work was supported by Tianjin Art Science Research Planning Project No. Q12067 in 2012.

\section{REFERENCES}

[1] Peiyi Song.Digital Media Assets Management[M]. China Radio and TV Press, 2009.

[2] Wenyi Yuan.The analysis of the core competitiveness of TV media[J]. Contemporary Communications,2006 (04) : 42-44. 
[3] Lan Li.The theory and case of TV industry value chain[M].Social Sciences Academic Press,2006:11.

[4] Li Cao.The main problems of Media Asset Management System[J]. China Radio and TV Academic Journal,2010.10

[5] Zhaowen Huang, Peiyi Song. Innovation mode of TV media business about digital media asset management[J].Television Studies,2012(12):43-45.

[6] Meng Nuo.Application of media asset management system for broadcasting and television[J].Video Engineering,2012(14):66-68.
[7] Englmaier,W.Version management in MAM systems[J].FKT.Die Fachzeitschrift fur Fernsehen, Film und Elektronische Medien,2012(4):175-180.

[8] Genzel, U. MAM and archiving in broadcast and media facilities[J]. Fernseh- und Kino-Technik,2008(3):93-99.

[9] Peiyi Song.Application Analysis of media asset management system in the production of television programs[J]. Modern TV Technology,2007(11) 